\title{
Pesquisando a pesquisa: uma autorreflexão sobre o campo comunicacional
}

\author{
Lygia Maria Rocha' \\ https://orcid.org/0000-0003-4733-6786 \\ I - PUC/SP-COS \\ São Paulo (SP). Brasil \\ MATTOS, M. A.; BARROS, E. J. M.; \\ EMILIANO, M. (orgs.). Metapesquisa \\ em comunicação: o interacional e seu \\ capital teórico nos textos da Compós. \\ Porto Alegre: Sulina, 2018, 422 p.
}

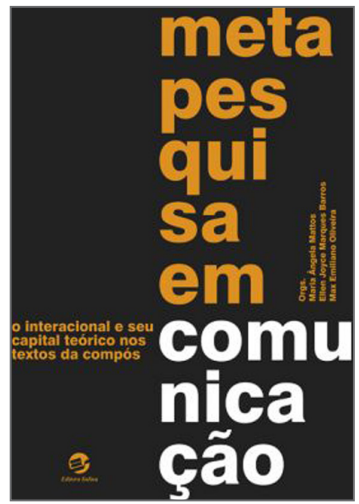

Resumo: O livro Metapesquisa em Comunicação: o interacional e seu capital teórico nos textos da Compós mostra o resultado da pesquisa coordenada pela professora Dra. Maria Ângela Mattos, do Programa de Pós-Graduação em Comunicação Social da PUC-MG, que efetuou uma análise da produção científica apresentada em congressos da Associação Nacional de Programas de Pós-Graduação em Comunicação (Compós) realizados entre 2000 e 2011. A pesquisa buscou compreender como pesquisadores se apropriam do estoque de conhecimento presente na literatura da área para analisar processos, dinâmicas e regimes de interação a partir da identificação de conceitos, objetos, e autores de referência acionados nos artigos apresentados na Compós. Assim, essa pesquisa possibilita verificar o capital teórico a respeito do conceito de interação circulante, legitimado no campo da comunicação, e também reconhecer os problemas e desafios da produção realizada nesse campo.

Palavras-Chave: metapesquisa; comunicação; Compós.

Abstract: Researching the research: a self-reflection on the communicational field - The book Meta-research in Communication: the interaction and its theoretical capital in the texts of Compós shows the result of the research coordinated by professor Dr. Maria ângela Mattos of the Post-Graduate Program in Social Communication at PUC-MG, which carried out an analysis of the scientific production presented in conferences of the National Association of Graduate Programs in Communication (Compós) carried out between 2000 and 2011. 
The research sought to understand how researchers appropriate the stock of knowledge present in the literature in the area to analyze processes, dynamics and interaction regimes based on the identification of concepts, objects, and reference authors used in the articles presented in Compós. Thus, this research makes it possible to verify the theoretical capital regarding the concept of circulating interaction, legitimized in the field of communication, and also to recognize the problems and challenges of the production carried out in this field.

Keywords: meta-research; Communication; Compós.

Em sua análise do campo científico, Bourdieu (1983, p. 122) afirma que esse, como qualquer outro campo, se estrutura como espaço de uma luta concorrencial entre pares/ concorrentes em busca do "monopólio da autoridade científica definida como capacidade técnica e poder social". Não apenas os atores do campo detêm diferentes níveis de capital científico (o capital simbólico específico do campo científico) - avaliados e legitimados através de títulos, anos de experiência, publicações, reverberação etc. -, como as áreas de conhecimento também se apresentam, a cada momento, de formas hierarquizadas. Assim, há áreas mais autônomas do que outras, ou mais legitimadas, mais valorizadas. Da mesma forma, no interior de uma mesma área, verificam-se relações hierárquicas entre objetos, teorias e metodologias. Segundo Bourdieu (1983, p. 133), o campo científico se define, portanto, pela "estrutura da distribuição do capital específico, resultado das lutas anteriores que se encontra objetivado nas instituições".

É notório que, no campo da ciência, verifica-se uma relação hierárquica entre a área das humanidades e a área das chamadas hard sciences. Bourdieu (1983) verifica isso e mostra como a própria área de humanas introjeta essa hierarquia quando tenta aplicar métodos e teorias das ciências exatas aos seus objetos de estudo, muitas vezes como forma de legitimação. Porém, dentro das humanidades, também é possível verificar relações hierárquicas entre disciplinas mais e menos autônomas, mais e menos consolidadas.

A área da comunicação lida com este tensionamento hierárquico e até mesmo com a desconfiança acerca de sua legitimidade como um específico campo de conhecimento. Braga (2018) lembra, por exemplo, que na maioria das instituições da Europa, a pesquisa em comunicação se espraia pelos diversos cursos de humanidades. Já no Brasil nota-se a reunião das perspectivas comunicacionais em um mesmo âmbito. A desconfiança também se relaciona com a profícua diversidade do campo da comunicação, que pode ser interessante sob o ponto de vista teórico e metodológico, mas que leva a uma dispersão em termos de objetos e abordagens. Por sua vez, a interdisciplinaridade, uma característica notável do campo, pode levar a um embotamento na elaboração de métodos e teorias criativas e inovadoras específicas para a área de comunicação - já que esta pode se ver subjugada a clássicas teorias e métodos de campos científicos mais tradicionais, como o das ciências sociais.

Por isso, a pesquisa coordenada pela professora Dra. Maria Ângela Mattos, no grupo de pesquisa Campos Comunicacionais e suas Interfaces, do Programa de 
Pós-Graduação em Comunicação Social da PUC-MG, se torna de fundamental importância. O resultado da primeira parte da pesquisa foi lançado no livro Metapesquisa em comunicação: o interacional e o seu capital teórico nos textos da Compós. Trata-se de uma reflexão do campo da comunicação sobre si mesmo. Uma pesquisa de fôlego que analisa 126 artigos apresentados em seis grupos de trabalho (GTs) da Compós (Congresso da Associação Nacional dos Programas de Pós-Graduação em Comunicação) durante a primeira década de 2000.

Para conseguir analisar um objeto tão amplo e complexo como esse, o cuidado com as operações metodológicas torna-se prioritário. Nesse ponto, chama atenção a forma criativa pela qual foram feitos o recorte e o sistema de análise do corpus. A pergunta norteadora foi: "O que há de interacional nesses textos?". O critério qualitativo, portanto, abrangeu artigos que analisavam os processos interacionais especificamente a partir de uma perspectiva comunicacional: “...ou seja, que compreende a comunicação como questão central do estudo, e não como coadjuvante" (MATTOS, 2018, p. 41). O objetivo é capturar a diversidade das perspectivas comunicacionais que se debruçam sobre os processos interacionais, midiatizados ou não.

É importante notar que a pesquisa organizou os artigos não a partir dos temas dos GTs, mas, efetuando uma análise transversal, agrupou os textos em eixos de investigação. Assim, foram identificados oito eixos: Sociocultural (30 artigos); Cibercultural (28 artigos); Midiatização (16 textos); Comunicação e Interação Mediada (12 textos); Epistemológico (11 textos) Sociopolítico (10 artigos); Críticas da Comunicação (10 artigos); e Sociodiscursivo (9 textos).

Essa organização foi realizada de forma imanente, não apriorística. O grupo de pesquisa deixou que o objeto, por assim dizer, falasse e, a partir dessa fala, foi percebendo aproximações e distanciamentos entre os textos. Por exemplo, no eixo Sociodiscursivo, há textos que foram apresentados em três diferentes GTs da Compós: três textos no GT Comunicação e Sociabilidade; três textos no GT Recepção: processos de interpretação, uso e consumo midiático; e dois textos no GT de Comunicação e Cultura. Além disso, dentro de um mesmo eixo, foram identificadas subdivisões a partir de diferentes abordagens. Ainda no exemplo do eixo Sociodiscursivo, verificou-se três enfoques distintos: 1) semiótica das interações sociais; 2) o estudo dos discursos; 3 ) a estética da recepção.

Em cada eixo investigativo, segue-se uma sequência analítica. Primeiro, é feita uma fundamentação teórica geral relativa àquele eixo, explicitando as principais escolas, autores mais relevantes, principais objetos, conceitos, tensões e discordâncias internas etc. Em seguida, apresenta-se a análise do corpus a partir das subdivisões, mostrando quais autores, teorias, metodologias e objetos foram acionados pelos autores dos artigos. Por último, há considerações gerais e críticas sobre o capital teórico relativo às interações no respectivo eixo de investigação.

Dentre os autores acionados no eixo Sociodiscursivo, temos Thompson, Giddens e Landowski, na subdivisão Semióticas das Interações Sociais; Véron, Ranciére, Habermas, Certeau, Bauman, e outros, na subdivisão Estudos do Discurso; e Iser, Bordini e Aguiar, 
Jauss, e Ziberman, na subdivisão Estética da Recepção. Os objetos trabalhados são variados, incluindo programas de TV, publicidade, espaços públicos, coletivos da web etc. Com relação à articulação conceitual, verificou-se uma preocupação com o tensionamento dos regimes de interação propostos por Landowski, uma ruptura das fronteiras entre produtor/receptor ou enunciador/enunciatário, a superação do conceito de contrato de leitura pelo de zonas de contato, a visão da interação como experiência de produção de sentido e de que o próprio ato da interação é gerador de processos de significação.

Apesar de ter o menor número de artigos do corpus (apenas nove), segundo os autores da metapesquisa, o eixo Sociodiscursivo apresenta grande relevância na construção do capital teórico das interações comunicacionais, principalmente pelo acionamento da noção de discurso, que sempre pressupõe uma relação e uma operação de semiose. Nesse sentido, revela-se uma postura que une três diferentes perspectivas epistemológicas: a social, a semiótica e a comunicacional. Nessa triangulação, conjuntamente com a análise de objetos que vão desde a comunicação face a face, em ato, até a midiatizada e mediada, o eixo Sociodiscursivo contribui para dar centralidade ao conceito de interação.

De modo geral, nos oito eixos de investigação, a metapesquisa verifica múltiplas interfaces da comunicação com saberes de outras áreas do conhecimento e infere que "o capital teórico das interações se mostra ainda disperso e pulverizado (em processo mesmo de constituição)" (MATTOS; BARROS; OLIVEIRA, 2018, p. 331). O principal desafio é se apropriar da interdisciplinaridade sem perder de vista o horizonte comunicacional, o que se torna fundamental em um ambiente social, político e econômico cada vez mais regido por interações comunicacionais, mediadas e midiatizadas. Outro ponto importante que a metapesquisa revela é a presença ainda constante de uma antiga disputa na área da comunicação - aquela analisada por Umberto Eco (1986) - entre apocalípticos - aqueles que veem as novas tecnologias da informação e da interação como propulsores de diversos problemas políticos e sociais -, e os integrados - que verificam uma enorme potência democrática nos meio contemporâneos de interação e comunicação.

Lygia Maria Rocha é doutoranda no Programa de Estudos Pós-graduados em Comunicação e Semiótica da PUC-SP.

lymariarocha@gmail.com

\section{Referências}

BOURDIEU, P. O campo científico. In: ORTIZ, R. (org.). Pierre Bourdieu: sociologia. São Paulo: Editora Ática, 1983 
BRAGA, J. L. Interfácio. In: MATTOS, M. A.; BARROS, E. J. M.; OLIVEIRA, M. E. (org.). Metapesquisa em comunicação: o interacional e seu capital teórico nos textos da Compós. Porto Alegre: Sulina, 2018.

ECO, U. Apocalípticos e Integrados. São Paulo: Perspectiva, 1986.

MATTOS, M. A.; BARROS, E. J. M.; OLIVEIRA, M. E. (org.). Metapesquisa em comunicação: o interacional e seu capital teórico nos textos da Compós. Porto Alegre: Sulina, 2018.

À guisa de constituição do corpus e do método. In: MATTOS, M. A.; BARROS, E. J. M.; OLIVEIRA, M. E. (org.). Metapesquisa em comunicação: o interacional e seu capital teórico nos textos da Compós. Porto Alegre: Sulina, 2018.

Resenha recebida em 15/11/2019

e aprovada em 01/12/2019. 